This is a pre-published manuscript of an article published by Taylor and Francis in Acta Agriculturae Scandinavica, Section B - Soil and plant science, on 24 May 2012, available online: http://www.tandfonline.com/doi/

\title{
Priorities for sustainable turfgrass management: a research and industry perspective
}

\begin{abstract}
This paper provides a brief review and assessment of the key environmental, regulatory and technical issues facing the turfgrass sector with specific reference to the European context. It considers the range of externalities or 'drivers for change' facing the industry, and the challenges and opportunities available for promoting and achieving more sustainable turfgrass management within the sports, landscape and amenity sectors. The analysis confirms that there are a number of key areas where a concerted research and industrial effort is required. These include responding to the pressures from government demands for greater environmental regulation, the increasing pressure on natural resources (notably water, energy and land), the emerging role of turf management in supporting ecosystem services and enhancing biodiversity, the continued need to promote integrated pest management, and the looming challenges posed by a changing climate, and urgent need to adapt. Whilst many of these externalities appear to be risks to the sports turf industry, there will also be significant opportunities, for those where the labour, energy and agronomic costs are minimized and where the drive to adopt a multifunctional approach to sportsturf management is embraced.
\end{abstract}

Keywords: Ecosystem services, golf courses, integrated pest management, landscape amenity, natural resources, sport fields.

\section{Introduction}

Managed turfgrass areas such as golf courses, sports fields, landscaped amenity areas and public parks all provide an important social, environmental and economic resource for both urban and rural communities. They serve a multifunctional purpose, by offering valuable open spaces for recreation, helping to improve the health and quality of life of individuals, and when designed and managed appropriately, can enhance biodiversity and support regulatory targets for environmental protection. Conversely, where turfgrass management practices are inadequate or inappropriate, their services to society are reduced, and their impacts on the natural environment can be damaging and costly.

The challenges for the future of turfgrass management are many and diverse. The increasing demands on natural resources (notably land, water resources and energy) driven by economic development and population growth, coupled with government demands for greater environmental protection are creating conflicts at the interface between land management (including turfgrass) and the environ- ment. The situation is particularly acute in periurban areas where the majority of managed turfgrass facilities are concentrated and in arid and semi-arid regions (including southern Europe) where the pressures on natural resources are most stressed. Population growth, migration and climate change will further exacerbate the current situation, by increasing the competition for resources between individual sectors, including agriculture, urban development, tourism and the environment. The challenge is how turfgrass facilities will respond and adapt to rising operating costs for inputs including labour, energy and fertilizer (Rodríguez Díaz et al. 2010).

The key for the future sustainable management of turfgrass will be to increase resource-use efficiency, reduce management costs and minimize environmental impact. In this context, the protection and enhancement of ecosystem services will need to be fully integrated into the planning, design, construction and management of all turfgrass facilities. This paper outlines the key environmental, regulatory and technical issues facing the turfgrass sector with 


\section{M. Strandberg et al.}

specific reference to the European context, the external 'drivers for change' and the challenges and opportunities for promoting and achieving the sustainable management of turfgrass within the sports, landscape and amenity sectors.

\section{Drivers for change}

Over the next decade, the turfgrass industry faces a number of major challenges. In Europe, probably the greatest risks to the sector relate to the raft of new and existing environmental regulation. In recent years, a number of new European Directives have been passed, including the Water Framework Directive (WFD 2000/60/E), which became law in December 2000 and was then transposed into Member State law in 2003. Its implementation is an ongoing process, with some key issues yet to be defined, but it will become 'active' on stakeholders in 2012 when the first approved River Basin Management Plans (RBMP) are operationalized across Europe.

Despite its title the WFD is as much about land management as it is about water management. It is the most substantial piece of water legislation produced by the European Commission and will provide the major driver for achieving sustainable management of water across all Member States. It requires that all inland and coastal waters within defined river basin districts must reach at least 'Good' status by 2015 and defines how this should be achieved through the establishment of environmental objectives and ecological targets for surface waters. The WFD applies to all waters and aims to tackle diffuse source pollution (for example, ranging from fertilizer and pesticide applications on turfgrass areas to urban run-off). It introduces the concept of ecological water quality for the first time including hydromorphological aspects, and it demands costeffective measures and full cost recovery. Although the WFD will be implemented at the river basin level, it is unlikely to have direct consequences on turfgrass facilities. However, as in agriculture, the heavy reliance on the use of fertilizers and pesticides in turfgrass management means that many facilities will be subject to much greater levels of national surveillance to ensure that diffuse pollution from turfed areas are not contributing to water pollution at the local catchment scale. Although agriculture is widely viewed as the key target for change, it is inevitable that in small catchments where turfgrass is an important component of land use, then there is likely to be much greater monitoring of turf management practices. However, the rising costs for fertilizer and pesticides are themselves acting as an industry brake on diffuse pollution with many turfed facilities actively investigating options to reduce their dependence on chemicals, and seeking understanding from those using the facilities to appreciate the necessity for changes in turfgrass management. Rising energy costs will also have a direct impact on the cost and dependence of fertilizer use in turfed areas. Collectively, these may in fact provide a positive indirect response to the WFD and other related EU Directives.

In addition to the WFD, in 2009 the Directive 2009/128/EC of the European Parliament and Council established a framework for Community action to achieve the sustainable use of pesticides, and a Council Directive 92/43/EEC on the conservation of natural habitats and of wild fauna and flora. Whilst many of these are intended to be implemented at the river basin or catchment scale their impact will be felt at the individual business level, particularly where facilities are in water-stressed catchments and/or in close proximity to protected habitats or environmentally designated sites, such as Special Areas of Conservation (SAC).

\section{Environmental protection}

Governments and society are seeking to achieve greater levels of environmental protection. All sectors including turfgrass management will inevitably be subject to increasing levels of environmental regulation and monitoring. As a consequence, turfgrass facilities are under increasing scrutiny to demonstrate compliance with national and European regulations, including for example, the various EU Directives mentioned above relating to habitats, water, soil, nitrates, pollution and pesticides.

Although there are many examples of best practice within specific turfgrass sectors (e.g. R\&A Best Practice in Golf) there are also well-publicized examples of mal-practice, and hence significant opportunities to improve existing levels of management, knowledge and awareness across the broader turfgrass industry. There are always opportunities to move the 'average' turfgrass manager nearer to 'the best' (benchmarking) and the turfgrass industry should take a lead in training, knowledge transfer and dissemination of best practice, not only for existing venues but also in leading innovation in the design and management of new golf courses, stadia and sports turf facilities. Driving industry improvement should become a priority with the regulatory 'stick' as the ultimate sanction.

\section{Natural resources}

The downward pressure on our natural resources and capital, including land, water and energy, is of major global concern. Reducing resource consumption and 
increasing resource efficiency will be key factors (Wheeler and Nauright 2006). From an industry perspective, it also makes business sense to reduce costs and waste through efficient consumption of water, energy, materials and fertilizers. In many regions, including humid environments, managed turfgrass areas require substantial quantities of water to optimize playability and bounce. But in many catchments across Europe, water resources are under intense pressure with many considered to be overexploited (European Environment Agency 2009).

The factors influencing water use in the sports turf sector, such as golf, vary markedly from those of other sectors dependent on irrigation abstraction (e.g. agriculture). In contrast to maximizing crop yield and quality, the main objective of sports-turf irrigation is to produce and maintain safe, highquality playing surfaces. On all modern golf courses for example, irrigation is an essential tool in the maintenance and management of the fine turf surfaces. It serves to control the growth and quality of the turf, to maximize playability and bounce, to maintain the aesthetic conditions required by players, and to deal with the vagaries of the summer weather. In other sectors, such as racecourses, irrigation serves to control the 'going' or soil moisture levels and to provide optimal conditions for racing whilst also minimizing the health and safety risks to riders. In providing an optimum playing surface, managers are also trying to alleviate compaction, maximize aeration and control drainage. Irrigation helps to achieve these goals. Although irrigation is important for optimizing turf growth (roots require both oxygen and water in the root zone to thrive) it is important in other ways. In particular, soil water content affects bounce and playability. It is also important for other sports turf management practices (e.g. fertilizer applications, top dressing).

Water allocations for turfgrass are also under pressure, given concerns regarding food security and the need to increase agricultural productivity (Rodríguez-Díaz et al. 2007). Consequently, managed turfgrass is under scrutiny to demonstrate greater water efficiency, through the uptake of new technologies, precision irrigation and novel approaches to turf management (e.g. deficit irrigation). Low levels of water management lead to nonbeneficial water losses and downstream environmental impacts on water quality, via nitrate and pesticide leaching. Higher nutrient-use efficiency must also be achieved in fertilizer use, with greater precision, both temporally and spatially, helping to maintain turf quality with reduced costs and lower environmental impacts via nitrate leaching. Efficient nutrient appli-
Priorities for sustainable turfgrass management

cation should aim to just meet actual demand of the turf (Ericsson et al. 2012a, 2012b).

In addition, intensely managed turfgrass might not only have to cope with decreased water availability, but also with decreasing water quality due to the use of recycled water/waste water for irrigation (Harivandi 2004). It is reported that many courses internationally are using waste water for irrigation and even where it has been subjected to various types of cleaning procedures, there may be problems with turf quality and grass growth (Bahri et al. 2001).

There are also conflicts in relation to reducing energy consumption in turf management whilst reducing dependence on the use of fertilizer and pesticides (Rodríguez-Díaz et al. 2010). Pesticidefree management means more mechanical management operations on grassed areas leading to increased $\mathrm{CO}_{2}$ emissions. Thus strategies to reduce the environmental impact of turf management in one area can have unexpected negative side effects in another area.

\section{Ecosystem services and biodiversity}

The conditions of our global society are also strongly influenced by our ability to live in harmony with ecosystems and to avoid the over-exploitation of natural resources. To halt the loss of biodiversity and the degradation of ecosystem services, more sustainable approaches to management for the benefit of both the natural environment and cultural landscape needs to be achieved (Government Offices of Sweden 2006, Nordic Council of Ministers 2008, European Union 2011). From an ecosystem management perspective, golf courses represent a promising measure for restoring and enhancing biodiversity in ecologically simplified landscapes, such as agricultural and urban lands. Golf courses offer real potential to be designed and managed to promote critical ecosystem services, such as for pollination and natural pest control, providing an opportunity for joint collaboration between conservation, restoration and recreational interests. Golf courses also have the potential to contribute to supporting wetland fauna, particularly in urban settings where they can contribute significantly to wetland creation (Colding and Folke 2009, Colding et al. 2009). This is not only the situation for golf courses but also for extensively managed turfgrass areas in urban and peri-urban areas which might be potential areas for conservation of biodiversity. The intensive use of the urban landscape can lead to destruction of foraging habitats for different bee species/populations (Franzén et al. 2009). For instance turfgrass areas where clover or other plants are included can support bee populations, which is a 


\section{$4 \quad$ M. Strandberg et al.}

major issue given the decrease in bee population in many European countries (Rasmont et al. 2005). Turfgrass areas might also support other ecosystem services in the local community. In this context, it is worth considering whether it is possible to attract new users to the different grass areas by including different activities/facilities. For example, placing fitness equipment on a turfgrass area will attract more users and provide wider health benefits to the society.

\section{Integrated Pest Management (IPM)}

The production of healthy turf, safeguarding environmental quality and providing a toxin-free environment is a high priority (European Union 2009). In this context, the turfgrass industry must play its part by reducing dependence on chemical plant protection products. The EU Directive has introduced an integrated approach to pest and disease management (IPM) as the driving force for producing healthy turf and reducing the use of pesticides. IPM is a decisionmaking process utilizing all suitable techniques to produce quality turf and minimize pest damages and pesticide use below those causing economically unacceptable damages or loss. In the future, management must be more focused, effective, structured and targeted. Using the principles of IPM for registration and documentation of turfgrass management is one option for the way forward. IPM can readily be applied to sport fields, golf courses and other areas where the management inspect the turfgrass areas on a regular basis. Implementation and success of IPM requires increased focus on education and development of documentation tools. In addition, research and development will be key. Using IPM as the driving force for a pesticide reduction will allow turfgrass management to contribute to the environmental goals given in the EU Directive (Strandberg et al. 2010).

\section{Adapting to climate change}

There is significant body of scientific evidence that the climate is changing, and growing concern on the impacts in specific sectors, including agriculture (e.g. Knox et al. 2010a, 2010b). However, for sports-turf management there is a notable lack of evidence on the direct impacts and range of adaptation options available. The major impacts are likely to relate to increased uncertainty in the pattern of rainfall, greater fluctuations in temperature and frequency in extreme events.

For turfgrass facilities investing in new infrastructure, including for example, new irrigation or drainage systems, many will need to factor in the costs of a changing climate, and develop appropriate adaptation strategies to cope with much greater uncertainty and extremes in rainfall and temperature. The impacts of climate change will not be constrained to only arid and semi-arid European areas (such as Spain, Portugal and Italy) but will also impact on turfgrass management in temperate and humid (northern Europe) regions. Climate change will also influence turfgrass growth and agronomy, with impacts on pest and disease control (coping with invasion of new pests and spread of existing diseases) and the need for irrigation and drainage, even in areas where previously rainfall might have been sufficient. Many sporting venues, by their very nature, are located in areas vulnerable to the increased frequency of flooding and droughts, being located on or close to river floodplains. A changing climate will also affect the use of turfed areas for sport and leisure - for example, warmer summer conditions may lead to much greater demand for particular leisure pursuits and increase the pressure on existing facilities, with consequent impacts on their management to maintain sward vigour, playability and aesthetic quality. These risks to the management of turfgrass facilities will thus not be confined to particular sectors or regions, but are likely to occur across both arid, temperate and humid environments to varying degrees.

During periods of heavy intense rainfall there will be a need for areas where water can be temporarily stored - areas where the water can attenuate without causing physical and economic damage to the local community. Golf courses or public parks might with some modifications become suitable areas for flood attenuation or storm water management. Whilst short periods of inundation may be acceptable, longer periods of turf flooding would increase disease risk, reduce turf quality and thus impact on playability. It also requires grass species to be adapted to submersion for a period of time. In Denmark, for example, the role of turfgrass areas in storm water management is now being evaluated.

The challenges to the turfgrass industry are not only caused by the demand for environmental protection, but also related to changes in management practices. A changing climate with more extreme weather will impact on current agronomic practices, and the challenge will be to identify appropriate short-term coping strategies and longer-term strategic developments. Key questions include, for example, how turfgrass managers should deal with areas that are used temporarily as storm water reservoirs; are the right grass species available for this purpose, and if so, how turfed areas can be managed to maintain high infiltration rates for ponded water. Conversely, during drought periods, 
what adaptation options are currently available to cope with extended periods of high temperature and/ or drought stress and how should turfed areas be managed during periods of irrigation abstraction restriction. A major challenge for the turfgrass industry is therefore to develop turfgrass varieties that can cope with these challenges in a realistic timescale.

There are many other factors related to a changing climate that need consideration. For example, an extended growing season due to warmer temperatures will result in increased mowing frequencies during the autumn and winter months. This may cause other problems, including compaction, leading to localized drainage problems and turf damage. Furthermore, more persistent summer droughts combined with wetter winters could also stimulate other turf problems, such as moss colonization. For example, in 2003, the summer drought in the UK was reported to have weakened many turf swards. The onset of a wet winter then resulted in the extensive moss colonization on many golf course greens and fairways (Windows 2003).

The seasonal changes in the distribution and intensity of rainfall are expected to have major impacts on sports turf management. More intense, frequent winter rainfall will necessitate better drainage to sustain playability during the winter months. Turfgrass managers may need to design drainage systems to cope with higher peak rainfall events, higher stream levels and water tables, and the increased flooding risk from local streams and rivers. Higher winter season precipitation will also lead to faster runoff, with implications for water quality.

Climate change could also indirectly impact on the types of turf used for golf course construction. For example, warm season grasses could become the preferred choice for temperate or humid summer conditions, although the threat from seasonal water logging could restrict plant growth and turf survival during the winter months. In South Europe, higher temperatures and prolonged periods of drought might call for new grass species that are adapted to more tropical-like conditions or the grasses used today need to be maintained differently with increased irrigation and use of fans (like in the USA) to cool the plants.

\section{Way forward}

It is apparent that the turfgrass industry faces a number of local and international challenges, all of which will need concerted and collective solutions, underpinned by robust, applied science. Three international and trans-disciplinary thematic areas have been identified, including (i) sustainable use of
Priorities for sustainable turfgrass management

natural resources, (ii) ecosystem services and biodiversity and (iii) integrated pest management. Collectively, these will lead to improvements in the quality of managed turfgrass areas as well as economic and environmental gains for the industry.

Like other land-based industries the turf industry has to take responsibility for sustainable societal development, i.e. produce turfgrass of a high standard whilst at the same time ensuring the sustainable use of natural resources and contributing to functioning ecosystems. When the turf industry takes responsibility for sustainable development, this creates a range of positive effects that are in demand in society. Examples of this include alternative employment to work in agriculture and forestry, increased opportunities for recreation and encounters with nature, increased natural and cultural values in the cultivated landscape, increased biological diversity in urban regions and purification of urban wastewater and surplus water.

In order to deal with the challenges the sector faces, there is a need for new knowledge within a number of key areas and thus structured, efficient work on the environment and sustainable development. In order to secure essential new knowledge, the industry must continue to invest in research and development (R\&D) to help underpin industry progress and improvement. A good example of this is the Scandinavian Turfgrass and Environment Research Foundation (STERF), which represents the Nordic golf federations' joint research body. This organization has prioritized $\mathrm{R} \& \mathrm{D}$ within four international and interdisciplinary thematic areas, including:

(i) Integrated pest management. Working with the turfgrass industry, the park and golf sector, universities and research institutions and authorities it takes responsibility for ensuring that $R \& D$ activities that are important for integrated pest management (IPM) are coordinated and executed and that new knowledge is delivered.

(ii) Sustainable water management. The goal here is to provide a science-based information gateway on integrated management practices, based on existing knowledge and outputs from new research, to improve resource efficiency, reduce water consumption, protect water quality and monitor impacts - both positive and problematic - of well-managed turfgrass areas on water resources management.

(iii) Muntifunctional use of golf courses and other turfgrass areas. Through utilizing expertise from various sectors, STERF wants to make the Nordic area an exemplar region as regards 


\section{M. Strandberg et al.}

multifunctional golf courses and collaborations between different interests in society.

(iv) Winter stress management. Winter damage is the foremost reason for dead grass, reducing the aesthetic and functional value of turf. UN climate scenarios predict that due to high precipitation and unstable temperature, ice and water damage will become the most important cause of winter damage in the future. The turfgrass industry must take responsibility for developing strategic expertise and new knowledge to avoid and manage such damage.

There is a need for pure research projects and also for demonstration trials under different climate conditions in order to gain a fundamental understanding of the issues within turfgrass management. STERF, together with the turfgrass industry, universities, research institutions and authorities, can take responsibility for ensuring that $\mathrm{R} \& \mathrm{D}$ activities that are important for construction and management of turfgrass areas are carried out and that new knowledge is delivered. Selected R\&D priority areas include:

Turfgrass breeding and evaluation. Breeding of new varieties and evaluation of species, varieties and seed mixtures will enable the sector to (i) find turfgrass species and varieties with greater stress tolerance (disease, wear, drought, temperature, shade) suited to IPM under different climatic conditions, and (ii) develop recommendations for selecting turfgrass and composing optimal turfgrass seed mixtures.

Control of diseases, pests and weeds. $\mathrm{R} \& \mathrm{D}$ on disease control, weeds and pests will enable the turfgrass sector to (i) recommend construction and management strategies based on IPM, including genetic, cultural, mechanical and biological alternatives, that can replace or minimize pesticide dependence (herbicides, fungicides and insecticides), (ii) be at the forefront in developing construction and management strategies that meet the demands of public authorities and general public, and (iii) provide the industry with the latest technology concerning more efficient pesticides and the least risk of environmental damage. Efficient use of energy, water and plant nutrients. $\mathrm{R} \& \mathrm{D}$ in the area of efficient use of energy, water and plant nutrients will enable the sector to (i) reduce energy consumption, especially fossil fuels, including the role of benchmarking (RodríguezDíaz et al. 2010), (ii) better understand the water and nutrient requirements of different grass species, and (iii) develop construction and maintenance strategies to minimize resource inputs and reduce pollution risks and achieve the necessary standards in playing quality.

Ecosystems, biodiversity and cultural preservation. $\mathrm{R} \& \mathrm{D}$ on co-existence with the environment and maintaining the natural and cultural value of golf courses will enable the golf sector to (i) develop guidance to demonstrate how ecosystem protection and enhancement and cultural preservation can be fully integrated into golf facility planning, design, construction and management, (ii) document and evaluate the effects of golf courses on biodiversity and the natural and cultural value of the landscape, and(iii) demonstrate with credibility that golf courses can fulfil important biodiversity and nature conservation functions, and can bring positive cultural values to the landscape.

Multifunctional use of golf courses and turfgrass areas. $\mathrm{R} \& \mathrm{D}$ on multi-functionality will enable the sector to (i) increase the benefits of managed turfgrass areas to society, (ii) help maintain the values of ecosystem services; and (iii) improve the business gains from multifunctional activities.

To achieve these benefits and improvements in the sustainable management of turfgrass requires active industry engagement and effective knowledge transfer and outreach. The results from turfgrass research therefore need to be made easily accessible to endusers and support provided to implement change. This places a great emphasis on effective communication of R\&D activities and their outputs. Research bodies need to ensure that their project outputs are presented in formats that are practically applicable and embedded within programmes of measures and recommendations for management change. The key will be in ensuring that research findings are made available to all interested parties, disseminated widely to maximize outreach and that their impacts are quantified for the benefits of the turfgrass industry.

\section{References}

Bahri, A., Basset, C., Oueslati, F., \& Brissaud, F. (2001). Reuse of reclaimed wastewater for golf course irrigation in Tunisia. Water Sciences and Technology, 43(10), 117-124.

Colding, J., \& Folke, C. (2009). The role of golf courses in biodiversity conservation and ecosystem management. Ecosystems, 12, 191-206.

Colding, J., Lundberg, J., Lundberg, S., \& Andersson, E. (2009). Golf courses and wetland fauna. Ecological Applications, 19(6), 1481-1491.

Ericsson, T., Blombäck, K., \& Neumann, A. (2012a). Demand driven fertilisation. Part I: Nitrogen productivity in four high maintenance turf grass species. Submitted to Acta Agriculturae Scandinavica Section B - Soil and Plant Science.

Ericsson, T., Blombäck, K., Kvalbein, A., \& Neumann, A. (2012b). Demand driven fertilization. Part II: Influence of 
demand driven fertilization on shoot nitrogen concentration, growth rate, fructan storage and playing quality of golf turf. Acta Agriculturae Scandinavica Section B - Soil and Plant Science, in press.

European Environment Agency (2009). Water Resources across Europe: Confronting Water Scarcity and Drought. Copenhagen: European Environment Agency.

European Union (2009). Directive 2009/128/EG of the European Parliament and of the Council from 21 October 2009, on establishing a framework for Community action on achieving a sustainable use of pesticides. Brussels: EU.

European Union (2011). Communication from the Commission to the European Parliament, the Council, the economic and social committee and the committee of the regions - Our life insurance, our natural capital: an EU biodiversity strategy to 2020. COM (2011) 244 final. Brussels: EU.

Franzén, M., Larsson, M., \& Nilsson, S. G. (2009). Small local population sites and high habitat patch fidelity in a specialized solitary bee. Fournal of Insect Conservation, 13, 89-95.

Government Offices of Sweden (2006). Environmental quality objectives - a shared responsibility. http://www.sweden.gov.se/ $\mathrm{sb} / \mathrm{d} / 5775$

Harivandi, A. (2004). Evaluating recycled waters for golf course irrigation. Green Section Record, Nov-Dec, 25-29.

Knox, J. W., Morris, J., \& Hess, T. M. (2010a). Identifying future risks to UK agricultural crop production - putting climate change in context. Outlook on Agriculture, 39(4), 249-256.
Priorities for sustainable turfgrass management

Knox, J. W., Rodríguez Díaz, J. A., Nixon, D., \& Mkhwanazi, M. (2010b). Climate change impacts on water use and productivity of sugarcane in Swaziland. Agricultural Systems, 103(2), 63-72.

Nordic Council of Ministers (2008). Environmental action plan 2009-2012. ANP 2008:733. Köpenhamn: NMR. http://www. norden.org/sv/publikationer/publikationer/2008-736.

Rasmont, P., Pauly, A., Terzo, M., Patiny, S., Michez, D., Iserbyt, S., Barbier, Y., \& Haubruge, E. (2005). The survey of wild bees (Hymenoptera, Apoidea) in Belgium and France. FAO-Report pp. 1-18.

Rodríguez-Díaz, J. A., Knox, J. W., \& Weatherhead, E. K. (2007). Competing demands for irrigation water: golf and agriculture in Spain. Irrigation and Drainage, 56, 1-9.

Rodríguez-Díaz, J. A., Weatherhead, E. K., García Morillo, J., \& Knox, J. W. (2010). Benchmarking irrigation water use in golf courses - a case study in Spain. Irrigation and Drainage, 60, 381-392.

Strandberg, M., Dahl Jensen, A-M., Dock Gustavsson, A-M., Tronsmo, A., \& Persson, P. (2010). Golf's research and development programme within integrated pest management. http://sterf.golf.se/extra/pod/?action $=$ pod show\&id $=106 \&$ module_instance $=1$.

Wheeler, K., \& Nauright, J. (2006). A global perspective on the environmental impact of golf. Sport in Society, 9(3), 427-443.

Windows, R. (2003). Adapt or die? Climate change - its impact on Scottish golf courses. Turfgrass Bulletin, 222, 5-7.
635

640

645

650

655

660 